\title{
Suatu Kajian Tentang Grup Fuzzy
}

\author{
Muhammad Abdy ${ }^{1}$, Sukarna $^{1}$, dan Rahmah Abubakar ${ }^{1, \text { a) }}$ \\ ${ }^{1}$ Jurusan Matematika, FMIPA Universitas Negeri Makassar, 90224 \\ a) e-mail: rahmahmathsains@gmail.com
}

\begin{abstract}
Abstrak.Penelitian ini mengkaji konsep dasar grup fuzzy dari grup klasik yang telah diperkenalkan oleh Azriel Rosenfeld, yaitu melihat hubungan antara sifat-sifat pada grup klasik dan sifat-sifat grup fuzzy. Ditunjukan bahwa Teorema 7 tidak berlaku di grup fuzzy.
\end{abstract}

Kata Kunci: Himpunan Kabur, Grup, Subgrup, Grup Fuzzy

\begin{abstract}
This research aims to review the basic concept of fuzzy group from classic group that have been introduced by Azriel Rosenfeld, and in addition,to find the connection between the properties of classic group and properties of fuzzy group. Show that the Theorem 7 is can't be applied in fuzzy group.

Keyword: Fuzzy set, Group, Subgroup, Fuzzy Grup
\end{abstract}

\section{PENDAHULUAN}

Dewasa ini matematika salah satu disiplin ilmu yang telah mengalami perkembangan pesat. Terbukti telah ditemukannya berbagai sub ilmu yang mendalami ketidakpastian dari keanggotaan suatu himpunan seperti himpunan fuzzy (fuzzy set) yang diperkenalkan oleh (Zadeh, 1965). Sejak kemunculannya, teori fuzzy terus berkembang dan telah banyak diterapkan dalam berbagai bidang ilmu, seperti komputer sains (Magdalena, Verdegay, \& Jose, 2015; Janssen, Schockaert, Vermeir, \& Cock, 2012), serta cabang ilmu matematika sendiri (misalnya bidang aljabar).

Hampir Sembilan belas abad manusia menggunakan operasi aljabar matematika hanya dalam himpunan tegas (nonfuzzy set). Namun, sejak teori himpunan fuzzy ditemukan, banyak peneliti yang mulai mengkaji himpunan fuzzy dalam sifat-sifat aljabar maupun dalam operasinya. Misalnya grup fuzzy (Rosenfeld, 1971), special set linear algebra and special set fuzzy linear algebra(Kandasamy, 2010), topologi dan struktur aljabar di himpunan fuzzy (Rodabaugh, \& Klemet, 2003), dan nilai kebenaran aljabar dari tipe dua himpuan fuzzy (Harding, Walker, \& Walker, 2016).

Penelitian sebelumnya yang berkaitan dengan grup fuzzy yaitu (Rosenfeld, 1971) yang mengaplikasikan konsep dasar himpunan fuzzy pada konsep grup dengan menganggap bahwa subset dari suatu grup $\mathrm{G}$ adalah fuzzy dan operasi biner pada $\mathrm{G}$ adalah tidak fuzzy (nonfuzzy), (Mukherjee, \& Bhattacharya, 1985) tentang relasi fuzzy dan grup fuzzy, (Bhutani, 1993) tentang himpunan fuzzy, relasi fuzzy, dan grup fuzzy, (Malik, \& Modeerson, 1991) dengan judul tulisannya A Note on Fuzzy Relation and Fuzzy Group, dan (Yuan, 2004) dengan judul publikasi Fuzzy Group Based on Fuzzy Binary Operation. Pada penelitian ini, penulis mengkaji pada bagian konsep dasar grup fuzzy Azriel dan hubungan antara sifat-sifat pada grup klasik dan grup fuzzy.

Pada penelitian ini diberikan sifat-sifat dari grup yang berlaku pada grup fuzzy serta sifat-sifat pada grup yang tidak berlaku pada grup fuzzy. 


\section{Grup dan Subgrup}

Grup didefinisikan sebagai suatu himpunan tak kosong yang dilengkapi dengan operasi biner dan memenuhi beberapa aksioma tertentu sebagai berikut.

Definisi 1 (Tahmir, 2004; Rosenfeld, 1971) Suatu sistem aljabar $\left(G,^{*}\right)$ dari himpunan tidak kosong $G$ dengan operasi biner *, dikatakan grup jika memenuhi sifat berikut.

$$
\begin{aligned}
& \text { i. } \quad \forall a, b, c \in G \text { berlaku } a *(b * c)=(a * b) * c . \\
& \text { ii. Adae } \in G \text { sehingga } \forall a \in G \text { berlaku } * e=e * a=a . \\
& \text { iii. } \forall a \in G, a d a a^{-1} \in G \text { sehingga } a * a^{-1}=a^{-1} * a=e .
\end{aligned}
$$

Adapun teorema yang digunakan (Rosenfeld, 1971) untuk merumuskan Definisi 1, dinyatakan sebagai berikut.

Teorema 2 (Tahmir, 2004; Janssen, dkk, 2012) Unsur identitas suatu grup adalah tunggal.

Teorema 3 (Tahmir, 2004; Janssen, dkk, 2012) Setiap anggota suatu grup mempunyai invers tunggal.

Teorema 4 (Tahmir, 2004; Janssen, dkk, 2012) Setiap grup memenuhi hukum pencoretan.

Misalkan $\mathrm{G}$ adalah grup dan $\mathrm{H}$ subset sebarang dari $\mathrm{G}$, maka $\mathrm{H}$ adalah komplex dari G. Perlu ditegasakan bahwa jika $\mathrm{G}$ bukan grup maka $\mathrm{H}$ bukan komplex dari G.Berikut diberikan definisi subgrup.

Definisi 5 (Tahmir, 2004; Rosenfeld, 1971) Suatu komplex tidak kosong H dari grup G dinamakan subgrup dari $\mathrm{G}$, jika $\mathrm{H}$ merupakan grup terhadap operasi yang sama di dalam $\mathrm{G}$.

Secara sederhana komlpex dari suatu grup dapat dinyatakan sebagai subgrup jika memenuhi sifat tertutup dan setiap unsurnya memiliki invers. Hal ini dinyatakan sebagai berikut.

Definisi 6 (Tahmir, 2004; Rosenfeld, 1971) Suatu komplex tidak kosong S dari grup G adalah subgrup jika dan hanya jika:.

$$
\begin{aligned}
& \text { i. } \quad x, y \in S \Rightarrow x y \in S . \\
& \text { ii. } \quad x \in S \Rightarrow x^{-1} \in S .
\end{aligned}
$$

Suatu komplex dari grup terhingga selalu membentuk subgrup sebagaimana berikut:

Teorema 7 (Tahmir, 2004; Janssen, dkk, 2012) Misalkan G grup terhingga dan $H$ komplex dari G, $H$ merupakan subgrup dari G jika dan hanya jika, untuk setiap $a \in H, b \in H$ maka $a b \in H$.

\section{Himpunan Fuzzy}

Misalnya $X$ adalah ruang dari objek-objek dan $\mathrm{x}$ adalah elemen dari X. Himpunan klasik $\mathrm{A}, \mathrm{A} \subseteq \mathrm{X}$ didefinisikan sebagai koleksi elemen-elemen atau objek-objek $\mathrm{x} \in \mathrm{X}$ sedemikian sehingga $\mathrm{x}$ memenui salah satu "termuat" atau "tak termuat" di A. Dengan mendefinisikan fungsi karakteristik untuk setiap elemen $\mathrm{x}$ di $\mathrm{X}$, maka kita dapat menyatakan himpunan klasik A dengan pasangan terurut $(\mathrm{x}, 0)$ untuk $\mathrm{x} \notin \mathrm{A}$ atau $(\mathrm{x}, 1)$ untuk $\mathrm{x} \in \mathrm{A}$. Berbeda dengan himpunan klasik di atas, himpunan fuzzy mempunyai nilai berkisar pada interval tertutup $[0,1]$, yang menyatakan derajat keanggotaan suatu elemen dalam himpunan yang diberikan (Nurdin, 2008). Secara sederhanan himpunan fuzzy didefinisikan sebagai berikut. 
Definisi 8 (Abdy, 2008) Misalkan $U$ adalah suatu himpunan semesta dengan $x \in U$. Suatu himpunan fuzzy $A^{c}$ dalam $U$ adalah himpunan pasangan-pasangan terurut elemen x dengan derajat keanggotaannya, yaitu

$$
A^{\circ}=\left\{\left(\mathrm{x}, \mu_{\text {\&o }}(x) \mid \mathrm{x} \in \mathrm{U}\right\}\right.
$$

$\mu_{\Varangle}$ merupakan fungsi keanggotaan yang memetakan setiap $x \in U$ ke interval [0,1]. Nilai dari $\mu_{\not \alpha}(x)$ dalam interval $[0,1]$ disebut nilai keanggotaan dari elemen x dalam ${ }^{k}$, sedangkan interval $[0,1]$ sendiri disebut ruang keanggotaan.

\section{METODE PENELITIAN}

Penelitian ini merupakan jenis penelitian dasar dengan metode kajian literatur atau kajian pustaka, yaitu melakukan pencarian informasi secara objektif dengan sumber data berupa literatur dari berbagai sumber informasi pustaka yang relevan dengan teori grup, baik teori grup himpunan tegas maupun teori grup himpunan fuzzy.Fokus kajian dalam penelitian ini ialah mengkaji konsep dasar dari grup fuzzy Azriel Rosenfeld serta melihat hubungan antara sifat-sifat pada grup klasik dan sifat-sifat pada grup fuzzy.

Adapun langkah-langkah yang dilakukan dalam penelitian ini adalah sebagai berikut:

1. Membuktikan beberapa teorema grup fuzzy dengan tujuan untuk melihat kesesuaiannya dengan teorema pada grup fuzzy.

2. Memberikan penyangkal bahwa teorema 7 tidak berlaku di grup fuzzy.

\section{HASIL DAN PEMBAHASAN}

\section{Grup Fuzzy}

Grup fuzzy Diperkenalkan (Rosenfeld, 1971), dimana ia menganggap bahwa subset dari suatu grup $\mathrm{G}$ adalah fuzzy dan operasi biner pada $\mathrm{G}$ adalah tidak fuzzy (nonfuzzy) (Yuan, 2004). Secara sderhana definisi grup fuzzy diberikan sebagai berikut.

Definisi 9 (Moderson, Bhutani, \& Rosenfeld, 2005) Misalkan $\widetilde{G}$ himpunan fuzzy di G. Maka $\widetilde{G}$ disebut suatu grup fuzzy dari $\mathrm{G}$ jika:

$$
\begin{aligned}
& \text { 1. } \mu_{\widetilde{G}}(x * y) \geq \min \left\{\mu_{\widetilde{G}}(x), \mu_{\tilde{G}}(y)\right\}, \forall x, y \in G \\
& \text { 2. } \mu_{\widetilde{G}}\left(x^{-1}\right) \geq \mu_{\widetilde{G}}(x), \forall x \in G
\end{aligned}
$$

Pertidaksamaan pada Definisi 9 merupakan fuzzifikasi (fuzzification) dari Teorema 6 (Wang, Ruan, \& Kerre, 2009). Selanjutnya diberikan Teorema 10 menunjukkan bahwa syarat (2) dari Definisi 9 sebagai berikut: (Moderson, 2005:7)

Teorema 10 (Moderson, dkk, 2005) Misalkan $\widetilde{G}$ grup fuzzy dari grup G. Maka $\forall x \in G$,

$$
\begin{aligned}
\text { i. } & \mu_{\widetilde{G}}(e) \geq \mu_{\widetilde{G}}(x) \\
\text { ii. } & \mu_{\tilde{G}}(x)=\mu_{\widetilde{G}}\left(x^{-1}\right)
\end{aligned}
$$

Dari Teorema 10 dapat dituliskan definisi grup fuzzy dengan lebih sederhanan sebagai berikut. 
Definisi 11 (Priya, Ramachandran, \& Nagalaksmi, 2013) Misalkan G grup. Suatu subset fuzzy $\widetilde{G}$ dari $\mathrm{G}$ disebut grup fuzzy dari $\mathrm{G}$ jika untuk setiap $x, y \in \mathrm{G}$,

$$
\begin{aligned}
\text { i. } & \mu_{\tilde{G}}(e) \geq \mu_{\widetilde{G}}(x) \\
\text { ii. } & \mu_{\tilde{G}}(x)=\mu_{\widetilde{G}}\left(x^{-1}\right)
\end{aligned}
$$

Contoh 12 Diberikan Z himpunan bilangan bulat membentuk grup dengan operasi penjumlahan dengan $\mathrm{e}=0$ dan $\tilde{Z}$ himpunan fuzzy dalam membentuk grup fuzzy dengan fungsi keanggotaan:

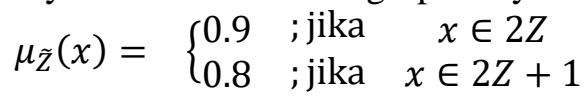

Contoh $\mathbf{1 3 Z}_{3}=\{\overline{0}, \overline{1}, \overline{2}\}$ membentuk grup dengan operasi penjumlahan dengan $e=\overline{0}$. Tunjukkan bahwa himpunan fuzzy $\widetilde{\mathbb{Z}}_{3}$ dalam $\mathbb{Z}_{3}$ tidak membentukk grup fuzzy dengan fungsi keanggotaan:

$$
\mu_{\widetilde{\mathbb{Z}_{3}}}=\left\{\begin{array}{cl}
1 & ; \text { jikax }=\overline{0} \\
0.8 & ; \text { jikax }=\overline{1} \\
0.6 & ; \text { jikax }=\overline{2}
\end{array}\right.
$$

Jawab Contoh 13 Perhatikan bahwa $\exists x \in \mathbb{Z}_{3}$ sehingga berlaku $\mu_{\widetilde{\mathbb{Z}_{3}}}\left(x^{-1}\right) \neq \mu_{\widetilde{\mathbb{Z}_{3}}}(x)$.

Ingat invers dari elemen $\mathbb{Z}_{3}, \exists x^{-1} \in \mathbb{Z}_{3}, \forall x \in \mathbb{Z}_{3}$ sehingga berlaku $x^{-1}=x^{-1}+x=e$.

Untuk $x=\overline{0} \Rightarrow x^{-1}=\overline{0}$

Untuk $x=\overline{1} \Rightarrow x^{-1}=\overline{2}$

Untuk $x=\overline{2} \Rightarrow x^{-1}=\overline{1}$

Perhatikan bahwa,

$$
\begin{gathered}
x=\overline{0} \Rightarrow \mu_{\widetilde{\mathbb{Z}_{3}}}\left(x^{-1}\right)=1=\mu_{\widetilde{\mathbb{Z}_{3}}}(x) \\
x=\overline{1} \Rightarrow \mu_{\widetilde{\mathbb{Z}_{3}}}\left(x^{-1}\right)=0.6 \neq 0.8=\mu_{\widetilde{\mathbb{Z}_{3}}}(x) \\
x=\overline{2} \Rightarrow \mu_{\widetilde{\mathbb{Z}_{3}}}\left(x^{-1}\right)=0.8 \neq 0.6=\mu_{\widetilde{\mathbb{Z}_{3}}}(x) \\
\therefore \mu_{\widetilde{\mathbb{Z}_{3}}}\left(x^{-1}\right) \neq \mu_{\widetilde{\mathbb{Z}_{3}}}(x), \forall x, \in \mathbb{Z}_{3} .
\end{gathered}
$$

Jadi $\widetilde{\mathbb{Z}_{3}}$ tidak membentuk grup fuzzy dengan operasi penjumlahan

Contoh 14G $=\left\{1, \omega, \omega^{2}\right\}$ membentuk grup dengan operasi perkalian dengan $e=1$. Tunjukkan himpunan fuzzy $\tilde{G}$ dalam $G$ tidak membentuk grup fuzzy, dengan fungsi keanggotaan: $\mu_{\tilde{G}}= \begin{cases}0.9 & \text {; jika } x=1 \\ 0.8 & \text {; jika } x=\omega \\ 0.6 & ; \text { jika } x=\omega^{2}\end{cases}$

Jawab Contoh 14 Perhatikan bahwa $\exists x, \in G$ sehingga $\mu_{\tilde{G}}\left(x^{-1}\right) \neq \mu_{\tilde{G}}(x)$

Ingat invers dari elemen grup $\mathrm{G} \exists x^{-1} \in G, \forall x \in G$ sehingga berlaku $x \times x^{-1}=x^{-1} \times x=e$.

Untuk $x=1 \Rightarrow x^{-1}=1$

Untuk $x=\omega \Rightarrow x^{-1}=\omega^{2}$

Untuk $x=\omega^{2} \Rightarrow x^{-1}=\omega$

Perhatikan bahwa,

$$
\begin{gathered}
x=1 \Rightarrow \mu_{\tilde{G}}\left(x^{-1}\right)=0.9=\mu_{\tilde{G}}(x) \\
x=\omega \Rightarrow \mu_{\widetilde{G}}\left(x^{-1}\right)=0.6 \neq 0.8=\mu_{\tilde{G}}(x) \\
x=\omega^{2} \Rightarrow \mu_{\tilde{G}}\left(x^{-1}\right)=0.8 \neq 0.6=\mu_{\widetilde{G}}(x)
\end{gathered}
$$




$$
\therefore \mu_{\tilde{G}}\left(x^{-1}\right) \neq \mu_{\tilde{G}}(x), \forall x, y \in G
$$

Jadi $G$ tidak membentuk grup fuzzy dengan operasi penjumlahan.

Berdasarkan Contoh 13 dan Contoh 14 diperoleh bahwa Teorema 7 tidak berlaku di grup fuzzy.

Teorema 15 setiap grup fuzzy memenuhi hukum pencoretan

Bukti Misalkan G grup dan $\widetilde{G}$ grup fuzzy di G dengan derajat keanggotaan $\mu_{\tilde{G}}$. Ambil sebarang $a, b, c \in \tilde{G}$ dengan derajat keanggotaan berturut-turut adalah $\mu_{\widetilde{G}}(a), \mu_{\widetilde{G}}(b), \mu_{\widetilde{G}}(c)$. Karena $\widetilde{G}$ grup fuzzy dari $\mathrm{G}$ maka $a, b, c \in \mathrm{G}$

Akan ditunjukkan bahwa

i. $\quad$ Jika $\mu_{\tilde{G}}(a * b)=\mu_{\tilde{G}}(a * c)$ maka $\mu_{\tilde{G}}(b)=\mu_{\tilde{G}}(c)$ (hukum pencoretan kiri)

ii. Jika $\mu_{\tilde{G}}(b * a)=\mu_{\tilde{G}}(c * a)$ maka $\mu_{\tilde{G}}(b)=\mu_{\tilde{G}}(c)$ (hukum pencoretan kanan)

3. Perhatikan bahwa

i. Jika $\mu_{\tilde{G}}(a * b)=\mu_{\tilde{G}}(a * c)$ maka $\mu_{\tilde{G}}(b)=\mu_{\tilde{G}}(c)$.

Jelas bahwa $a * b, a * c \in \widetilde{G}$ karena $\widetilde{G}$ mewarisi sifat tertutup dari G.

Pandang $\mu_{\tilde{G}}(a * b)=\mu_{\tilde{G}}(a * c)$.

Karena $a \in \tilde{G}, \tilde{G}$ grup maka $a^{-1} \in \tilde{G}$.

Perhatikan bahwa

$$
\begin{gathered}
\mu_{\tilde{G}}\left(a^{-1} *(a * b)\right)=\mu_{\tilde{G}}\left(a^{-1} *(a * c)\right) \\
\Rightarrow \mu_{\tilde{G}}\left(\left(a^{-1} * a\right) * b\right)=\mu_{\tilde{G}}\left(\left(a^{-1} * a\right) * c\right) \\
\Rightarrow \mu_{\tilde{G}}(e * b)=\mu_{\tilde{G}}(e * c) \\
\Rightarrow \mu_{\tilde{G}}(b)=\mu_{\tilde{G}}(c)
\end{gathered}
$$

Jadi diperoleh jika $\mu_{\widetilde{G}}(a * b)=\mu_{\widetilde{G}}(a * c)$ maka $\mu_{\widetilde{G}}(b)=\mu_{\widetilde{G}}(c)$ atau memenuhi hukum pencoretan kiri.

ii. Jika $\mu_{\tilde{G}}(b * a)=\mu_{\tilde{G}}(c * a)$ maka $\mu_{\tilde{G}}(b)=\mu_{\tilde{G}}(c)$.

Jelas bahwa $b * a, c * a \in \widetilde{G}$ karena $\tilde{G}$ mewarisi sifat tertutup dari G.

Pandang $\mu_{\tilde{G}}(a * b)=\mu_{\tilde{G}}(a * c)$.

Karena $a \in \tilde{G}, \tilde{G}$ grup maka $a^{-1} \in \tilde{G}$.

Perhatikan bahwa

$$
\begin{gathered}
\mu_{\tilde{G}}\left((b * a) * a^{-1}\right)=\mu_{\tilde{G}}\left((c * a) * a^{-1}\right) \\
\Rightarrow \mu_{\tilde{G}}\left(b *\left(a * a^{-1}\right)\right)=\mu_{\tilde{G}}\left(c *\left(a * a^{-1}\right)\right) \\
\Rightarrow \mu_{\tilde{G}}(b * e)=\mu_{\tilde{G}}(c * e)
\end{gathered}
$$

Jadi diperoleh jika $\mu_{\tilde{G}}(a * b)=\mu_{\tilde{G}}(a * c)$ maka $\mu_{\tilde{G}}(b)=\mu_{\tilde{G}}(c)$ atau memenuhi hukum pencoretan kanan.

Teorema 16 Misalkan $\widetilde{G}$ adalah suatu grup fuzzy dari $\mathrm{G}$ berlaku:

i. Jika $e^{`}$ identitas dari $\tilde{G}$ dan eunsur identitas di G maka $e^{`}=e$.

ii. Untuk setiap $a \in \tilde{G}$ dan misalkanbinvers $a$ di $\tilde{G}$ dancinvers $a$ diG makab $=c$.

Bukti misalkan $\widetilde{G}$ grup fuzzy di G.

i. Misalkan $e^{\prime} \in \tilde{G}$ unsur identitas dengan derajat keanggotaan $\mu_{\tilde{G}}\left(e^{\prime}\right)$ dan $e \in \mathrm{G}$ unsur identitas di G.

Akan ditunjukkan $e^{\prime}=e$.

Ambil sebarang $x \in \tilde{G}$ dengan derajat keanggotaan $\mu_{\tilde{G}}(x)$. Karena $\tilde{G}$ grup fuzzy dari $\mathrm{G}$ maka $x \in \mathrm{G}$.

Perhatikan bahwa

Jika $x \in \mathrm{G}$ dan $e$ identitas G maka $x * e=x$. 
Jika $x \in \tilde{G}$ dan $e^{\prime}$ identitas $\tilde{G}$ makax $* e^{\prime}=x$

Dengan demikian $x * e=x * e^{\prime} \Leftrightarrow e=e^{\prime}$.

Jadi $e=e^{\prime}$.

ii. $\quad$ Misalkan $e$ unsur identitas di $\tilde{G}$.

Berdasarkan (i) maka $e$ juga unsur identitas di G.

Ambil sebarang $a \in \tilde{G}$ dengan derajat keanggotaan $\mu_{\tilde{G}}(a)$. Karena $\tilde{G}$ grup fuzzy dari $\mathrm{G}$ maka $a \in \tilde{G}$.

Misalkan $b$ invers dari $a \in \tilde{G}$ dan $c$ invers dari $a \in \mathrm{G}$.

Perhatikan bahwa

Jika $b$ invers dari $a \in \tilde{G}$ maka $a b=e$.

Jika $c$ invers daru $a \in \mathrm{G}$ maka $a c=e$.

Dengan demikian $a b=a c \Leftrightarrow b=c$

Jadi $b=c$.

Teorema 17 Suatu grup fuzzy $\widetilde{G}$ dalam grup G memiliki identitas tunggal.

BuktiMisalkan $\tilde{G}$ adalah suatu grup fuzzy dalam grup $\mathrm{G}$ dengan derajat keanggotaan $\mu_{\tilde{G}}$.

Misalkan $e$ dan $e^{\prime}$ unsur identitas dari $\tilde{G}$ dengan derajat keanggotaan berturut-turut adalah $\mu_{\tilde{G}}(e)$, $\mu_{\tilde{G}}\left(e^{\prime}\right)$, karena $\tilde{G}$ grup fuzzy di G maka $e, e^{\prime} \in \mathrm{G}$.

Akan ditunjukkan $e=e^{\prime}$

Perhatikan bahwa

Karena $e$ unsur identitas di G dan $e^{\prime} \in \mathrm{G}$, maka $e * e^{\prime}=e^{\prime} * e=e^{\prime}$

Karena $e^{\prime}$ unsur identitas di $\mathrm{G}$ dan $e \in \mathrm{G}$, maka $e^{\prime} * e=e * e^{\prime}=e$

Berdasarkan (12) dan (13) diperoleh $e=e^{\prime}$.

Teorema 18 Setiap elemen dari grup fuzzy $\tilde{G}$ dalam grup G memiliki invers tunggal.

Bukti Misalkan $\tilde{G}$ adalah suatu grup fuzzy dalam grup G dengan derajat keanggotaan $\mu_{\tilde{G}}$.

Ambil sebarang $x \in \tilde{G}$ dengan derajat keanggotaan $\mu_{\tilde{G}}(x)$. Misalkan a dengan derajat keanggotaan $\mu_{\tilde{G}}(a)$, dan $b$ dengan derajat keanggotaan $\mu_{\tilde{G}}(b)$ invers dari $x$. Karena $\tilde{G}$ suatu grup fuzzy dalam grup $\mathrm{G}$ maka $x, a, b \in \mathrm{G}$.

Akan ditunjukkan bahwa $a=b$

Perhatikan bahwa

Karena $a$ invers dari $x$, maka $a * x=x * a=e$

Karena $b$ invers dari $x$ maka $b * x=x * b=e$

Dari (15) diperoleh $a *(x * b)=a * e=a$

Jadi $a *(x * b)=a$

Dari (14) diperoleh $(a * x) * b=e * b=b$

Jadi $(a * x) * b=b$

Karena grup memenuhi sifat assosiatif, maka dari (16) dan (17) diperoleh $a=a *(x * b)=$ $(a * x) * b=b$. Jadi diperoleh $a=b$ dengan kata lain invers dari setiap elemen $\tilde{G}$ tunggal.

\section{KESIMPULAN}

Berdasarkan hasil penelitian yang telah dipaparkan sebelumnya, dapat disimpulkan bahwa grup fuzzy merupakan perluasan dari konsep grup klasik, tepatnya konsep subgrup dari grup klasik, yaitu setiap grup dianggap memiliki subset fuzzy (Rosenfeld, 1971) Selanjutnya Definisi 9, yaitu definisi dari grup fuzzy merupakan fuzzifikasi dari Teorema 6. Secara umum sifat pada grup klasik berlaku pada grup fuzzy karena grup fuzzy memenuhi grup klasik. Seperti sifat ketunggalan identitas, ketunggalan invers, dan sebagainya. Namun ada beberapa sifat pada 
subgrup dari grup klasik yang tidak berlaku pada grup fuzzy misalnya Teorema 7 sebagaimana ditunjukkan pada Contoh 13 dan Contoh 14.

\section{DAFTAR PUSTAKA}

Zadeh, L. A. (1965). Fuzzy Sets. Information and Control, 8.338-353,

Magdalena,L. Verdegay, L., \& Jose, F. (2015). Esteva,"Enric Trillas: A Passion for Fuzzy Set: A Collection of Recent Works on Fuzzy Logic". Spinger International Publishing.

Janssen, J., Schockaert, S., Vermeir,D., Cock,M. D.(2012) “Answer Set Programming For Continuous Domains: A Fuzzy Logic Approach”, Atlantis Pers.

Rosenfeld, A. (1971). Fuzzy Groups. Journal of Mathematical Analysis and Applications, pp. 512-517, 1971.

Kandasamy, W.B. (2010).Special Set Linear Algebra and Special Set. Florentin Smarandache, K Ilanthenral,

Rodabaugh,S.E., \& Klemet, E. P. (2003).Topological and Algebraic Structures in Fuzzy Set. A Handbook of Recent Development in the Mathematichs of Fuzzy Sets.

Harding,J., Walker,C.L., \& Walker,E. (2016). The Truth Value Algebra of Type-2 Fuzzy Sets: Order Convolutions of Fungtion on The Unit Interval .CRC Press.

Mukherjee,N. P., \& Bhattacharya, P. (1985). Fuzzy Relations and Fuzzy Groups. Information Sciences 36. 267-282.

Bhutani, K. R. (1993). Fuzzy Sets, Fuzzy Relations, and Fuzzy Group: Some Interrelations. Information Seciences, 73. 107-115.

Malik,D.S., \& Moderson,J. N. (1991). A Note on Fuzzy Relations and Fuzzy Groups. Information Sciences, 56.193-198.

Yuan, X. (2004). Fuzzy Group Based on Fuzzy Binary Operation. Journal Computers and Mathematical with Applications, 47. 631-641,.

Tahmir, S. (2004). Teori Grup. Andira Publisher :Makassar.

Nurdin (2008). Pengantar Teori Fuzzy. Jurusan Matematika FMIPA UNM.

Abdy, M. (2008). Dasar-dasar Teori Himpunan Kabur \& Logika Kabur.Badan Penerbit Universitas Negeri Makassar: Makassar.

Moderson,J.N., Bhutani,K.R., \& Rosenfeld,A. (2005). Fuzzy Group Theory. Springer-Verlag Berlin Heidelberg: USA.

Wang, X., Ruan,D. E., \& Kerre, E. Mathematics of Fuzzy - Basic Issues. Springer.

Priya,T., Ramachandran,T., \& Nagalaksmi,K.T. On Q-Fuzzy Normal Subgroups. International Journal of Computer \& Organization Trend, 3(11). 2249-2593. 